\title{
Profundidade do solo e micro-relevo em bananais irrigados: impactos na nutrição mineral e potencial produtivo ${ }^{1}$
}

\author{
Soil depth and microrelief in irrigated banana plantation: impacts on mineral nutrition \\ and yield potential
}

\author{
Mirian Cristina Gomes Costa², Eurileny Lucas de Almeida ${ }^{3}$, Tiago Osório Ferreira², Daniel Pontes de Oliveira², \\ Ricardo Espíndola Romero ${ }^{2}$
}

\begin{abstract}
Resumo - O objetivo deste trabalho foi verificar o papel da profundidade do solo e da microtopografia em aspectos nutricionais e produtivos de bananais irrigados. O estudo foi conduzido na Chapada do Apodi (CE), em área com variações na profundidade do solo. Os tratamentos foram sítios (locais) em diferentes classes de micro-relevo (côncavo, convexo e retilíneo) que abrangeram quatro profundidades de solo: A) $0,92 \mathrm{~m}$; B) $0,77 \mathrm{~m}$; C) 0,65 m; D) 0,52 m. Foram avaliados: altura da planta mãe (APM), altura da planta filha (APF), diâmetro do pseudocaule da planta mãe (DPPM), massa de folhas frescas (MFF) e secas (MFS), teores de fósforo $(\mathrm{P})$, potássio $(\mathrm{K})$, cálcio $(\mathrm{Ca})$, enxofre $(\mathrm{S})$ e sódio $(\mathrm{Na})$ no tecido vegetal e massa dos cachos. $\mathrm{O}$ delineamento experimental foi inteiramente casualizado com sete repetições para avaliações de crescimento e cinco repetições para avaliações referentes à massa de folhas, estado nutricional e produção. A análise estatística foi feita pela ANOVA e DMS a 5\% de significância. APM e DPPM foram maiores em A e C, enquanto que menores médias ocorreram no solo mais raso (D). MFF e MFS foram superiores em A e D que também apresentaram maior acúmulo de nutrientes nas folhas. Entretanto, maiores teores foliares e níveis adequados de $\mathrm{P}$ ocorreram em A, que também apresentou maior massa de cachos em relação aos solos mais rasos. Isto mostra que a profundidade efetiva do solo e o micro-relevo influenciam a absorção de nutrientes, o crescimento e o potencial produtivo de bananeiras irrigadas na Chapada do Apodi.
\end{abstract}

Palavras-chave - Musa sp. Profundidade efetiva do solo. Macronutrientes. Semiárido cearense.

\begin{abstract}
The aim of this research was to verify whether soil depth affects aspects of mineral nutrition and yield potential of irrigated banana plantations. The study was carried out at Apodi Plateau (CE), Brazil, in an area characterized by soil depth variations. The treatments were sites in different microrelief classes (concave, convex and retilinea) with four different soil depths: A) $0.92 \mathrm{~m}$; B) $0.77 \mathrm{~m}$; C) $0.65 \mathrm{~m}$; D) $0.52 \mathrm{~m}$. The following measures were done: high of mother plant (APM), high of daughter plant (APF), pseudosterm diameter of mother plant (DPPM), weight of fresh (MFF) and dry leaves (MFS), contents of phosphorus $(\mathrm{P})$, potassium $(\mathrm{K})$, calcium $(\mathrm{Ca})$, sulphur $(\mathrm{S})$ and sodium $(\mathrm{Na})$ in plant tissue and bunch weight. Data were submitted to ANOVA and to least significant differences (LSD) with 5\% of significance. APM and DPPM were higher in A and C, while the lower values were found in the shallow soil (D). Values of MFF and MFS were higher in both sites A and $\mathrm{D}$ that also presented larger amount of nutrients in plant leaves. However, higher amount and adequate levels of $\mathrm{P}$ in plant leaves were observed in the site A, on which plants presented higher bunch weigth. It showed that effective soil depth and soil microrelief have influence in nutrients uptake, plants growth, and productive potential of banana plants irrigated at Apodi Plateau.
\end{abstract}

Key words - Musa sp. Effective soil depth. Macronutrients. Ceará semiarid region.

\footnotetext{
* Autor para correspondência

${ }^{1}$ Recebido para publicação em 23/07/2010; aprovado em 06/05/2011

Parte da Monografia de conclusão de curso do segundo autor apresentada ao Centro de Ciências Agrárias/UFC

2Departamento de Ciências do Solo/UFC, Campus do Pici, Fortaleza-CE, mirian.costa@ufc.br, tiago@ufc.br, daniel pontes78@hotmail.com, reromero@ufc.br

${ }^{3}$ Graduada em Engenharia Agronômica pela Universidade Federal do Ceará, Fortaleza-CE, Brasil, eurileny@gmail.com
} 


\section{Introdução}

O Brasil é o segundo maior produtor mundial de banana, com uma produção da ordem de 7.451.972 toneladas para o ano de 2010. A região Nordeste destacase como a maior produtora do país, sendo o estado do Ceará o terceiro maior produtor da região (IBGE, 2010).

Grande parte da produção de bananas no Ceará concentra-se no perímetro irrigado localizado na Chapada do Apodi que está inserida no polígono das secas (LEMOS et al., 1997). A região destaca-se em meio ao semiárido por apresentar alto potencial agrícola devido à presença de solos originados de calcário, com boa fertilidade natural e presença de relevo plano favorável à mecanização (DNOCS, 2009).

Porém, a região apresenta limitações quanto à manutenção e sustentabilidade dos recursos naturais, especialmente de seus solos. Similarmente ao que vem ocorrendo em outros perímetros irrigados, o uso intensivo dos solos associado à irrigação tem promovido o aparecimento de áreas afetadas pela aplicação excessiva de fertilizantes, ocorrência de erosão, compactação, além de áreas salinizadas (WEBER et al., 2006).

A maior parte dos problemas ligados à utilização inadequada dos solos na Chapada do Apodi está relacionada à carência de informações básicas sobre os solos da região. Os Cambissolos, que cobrem a maior parte da área, apresentam elevada variabilidade no que se refere às suas propriedades (LEMOS et al., 1997). Oliveira et al. (2009) encontraram elevada variação na profundidade dos solos da Chapada do Apodi em uma pequena escala espacial. De acordo com os autores, pequenas oscilações nas formas do relevo podem ser responsáveis pelo surgimento de solos com profundidades contrastantes em escala espacial reduzida. Alterações do micro-relevo podem proporcionar dinâmica hídrica distinta nos solos de uma mesma área, condicionando a gênese de solos distintos e uma distribuição diferenciada de atributos químicos e físicos (SOUZA et al., 2006).

Estudos destacam a importância da profundidade do solo como condicionante do crescimento de plantas (MEYER et al., 2007), da dinâmica hídrica (WANG et al., 2006), da produtividade de sistemas naturais (ROMANYA; VALLEJO, 2004) e do stand de plantas devido, essencialmente, à sua influência no volume de raízes e no conteúdo de água disponível. Diferenças na profundidade, mesmo que dentro de uma mesma classe de solo, podem influenciar o desenvolvimento das culturas. A redução do volume de solo desfavorece a movimentação da água de superfície e subsuperfície, podendo afetar ainda a disponibilidade de nutrientes e o crescimento radicular (SOUZA et al., 2008). Como as raízes são responsáveis pela sustentação das plantas e pela absorção de água e nutrientes (WAISEL et al., 2002), solos rasos podem limitar o estado nutricional e, conseqüentemente, a produtividade das culturas.

De 79 a $88 \%$ do sistema radicular de bananeiras de diferentes alturas concentram-se nos primeiros 45 $60 \mathrm{~cm}$ de profundidade, sendo $65 \%$ concentrado nos primeiros $30 \mathrm{~cm}$ (ARAYA, 2005). Qualquer situação que limite o desenvolvimento do sistema radicular, limitando a absorção de nutrientes, deve prejudicar a produtividade e a qualidade dos frutos.

Araya e Blanco (2001) estabeleceram relação direta entre profundidade do sistema radicular de bananeiras e o desenvolvimento de plantas. Estes autores destacam ainda a necessidade de estudos buscando elucidar a relação entre o desenvolvimento radicular e a produção de bananeiras. Assim, o objetivo do presente estudo é comprovar a hipótese de que profundidades diferenciadas de solos influenciam a absorção de nutrientes, afetando o crescimento e o potencial produtivo de bananeiras.

\section{Material e métodos}

O estudo foi realizado em bananal irrigado localizado na Chapada do Apodi (CE). A posição geográfica da área corresponde a $5^{\circ} 04^{\prime}$ latitude Sul e $37^{\circ}$ longitude Oeste. O clima da região, de acordo com a classificação de Köppen, é do tipo BSw'h' (quente e semiárido, com temperatura superior a $18^{\circ} \mathrm{C}$ no mês mais frio). As médias anuais de umidade relativa, temperatura e precipitação são $62 \%, 28,5^{\circ} \mathrm{C}$ e $772 \mathrm{~mm}$, respectivamente (DNOCS, 2009).

As avaliações foram feitas no ano de 2009, correspondente ao segundo ciclo de produção do bananal que foi estabelecido em 2008. Na área de estudo as bananeiras da cultivar "Williams" (Musa AAA subgrupo Cavendish) foram plantadas na mesma época, eliminando variações nas medidas de crescimento e produção em decorrência da época de plantio. As bananeiras foram plantadas em fila dupla, com espaçamento de 3,8 m entre filas duplas; $1,2 \mathrm{~m}$ entre linhas e 2,0 m entre plantas nas linhas simples.

Desde a implantação, a área foi irrigada por microaspersão, com água de poço classificada como $\mathrm{C}_{3} \mathrm{~S}_{1}$, apresentando salinidade entre $0,75-2,25 \mathrm{dS} \mathrm{m}^{-1} \mathrm{e}$ razão de adsorção de sódio (RAS) $<10\left(\mathrm{mmol} \mathrm{L}^{-1}\right)^{-0,5}$ (MAIA et al., 1998). O manejo da adubação foi feito por meio da fertirrigação, somado à adubação orgânica realizada anualmente com aplicação de composto orgânico. 
A escolha da área foi baseada em trabalho de Oliveira et al. (2009) que dividiram o terreno em compartimentos com superfícies côncava, convexa e retilínea (FIG. 1). Os autores determinaram a profundidade do solo em toda a área de estudo e também classificaram os solos de cada um dos compartimentos do relevo de acordo com o SiBCS (EMBRAPA, 2006).

Para a realização do presente estudo foram selecionados quatro sítios (A, B, C e D) ou locais de amostragem que estavam inseridos nos compartimentos côncavo, convexo e retilíneo. Conforme apresentado na Tabela 1, os sítios de amostragem englobaram três tipos de Cambissolos Háplicos.

Os quatro sítios foram considerados fatores de tratamento em delineamento inteiramente casualizado, com repetições representadas por plantas amostradas aleatoriamente em cada local. As profundidades efetivas de solo em cada sítio estudado foram: A) 0,92 m; B) 0,77 m; C) 0,65 m, e D) 0,52 m. Os parâmetros referentes à altura e diâmetro das plantas foram avaliados com sete repetições, enquanto que as informações referentes à massa de folhas, estado nutricional e produção foram avaliadas com cinco repetições.

Foi feita a caracterização química de amostras de solo coletadas em três profundidades $(0-20 \mathrm{~cm}, 20-40 \mathrm{~cm}$, 40-60 cm) em cada um dos sítios de estudo (A, B, C e D). Seguindo metodologias propostas por Embrapa (1997) foram extraídos fósforo $(\mathrm{P})$ e potássio $(\mathrm{K})$ por Mehlich 1 , com determinações por colorimetria $(\mathrm{P})$ e fotometria de chama $(\mathrm{K})$. Cálcio $(\mathrm{Ca})$, magnésio $(\mathrm{Mg})$ e alumínio $(\mathrm{Al})$ trocável foram extraídos por solução de $\mathrm{KCl} 1 \mathrm{~mol} \mathrm{~L}^{-1} \mathrm{e}$ determinados por espectrofotometria de absorção atômica

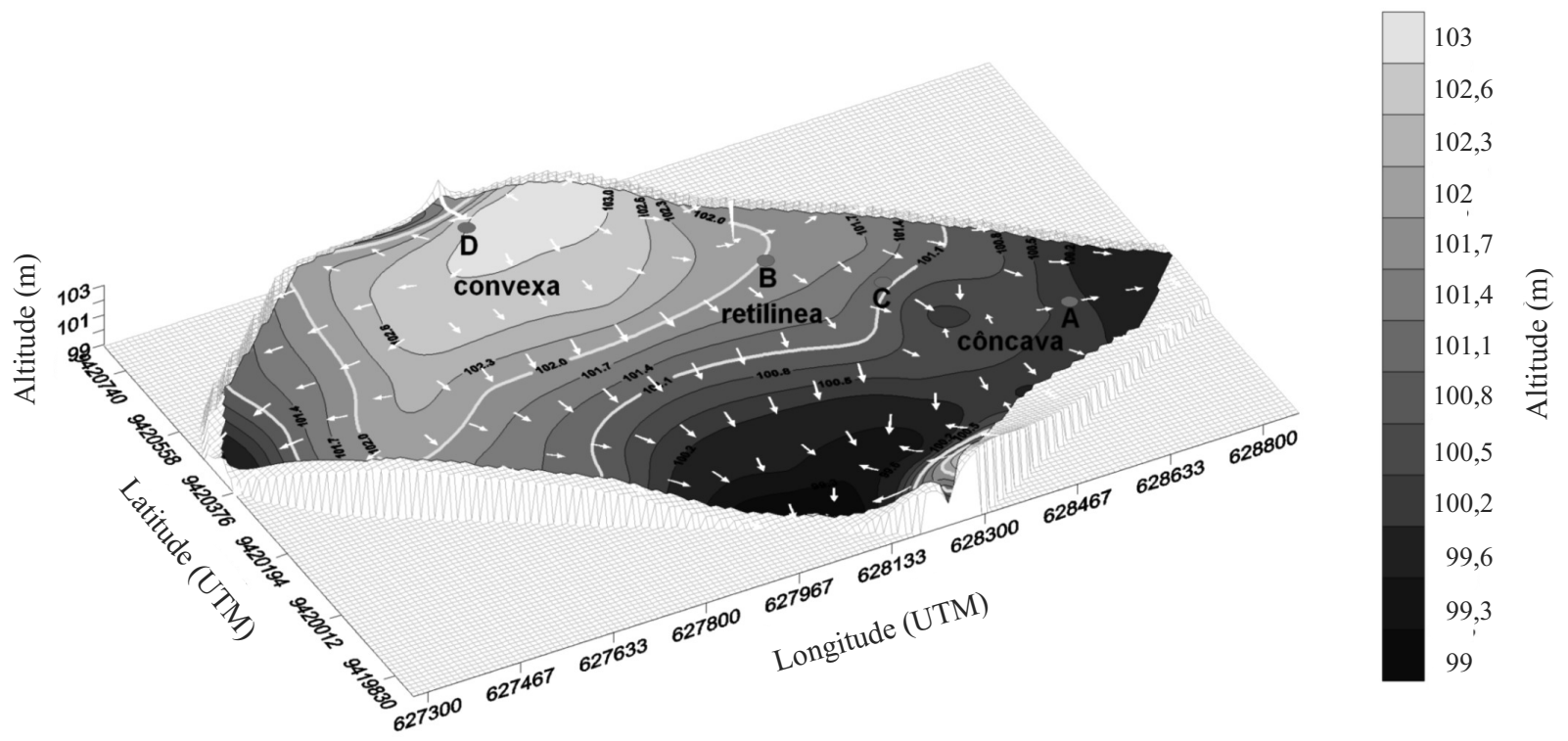

Figura 1 - Modelo de elevação digital da área de estudo representando os diferentes compartimentos do terreno, assim como a localização dos sítios analisados (A, B, C e D) e o fluxo preferencial de água

Tabela 1 - Localização e classificação dos solos da área de estudo (Fonte: Oliveira et al., 2009)

\begin{tabular}{|c|c|c|c|}
\hline Sítios & Localização & Superfície & $\begin{array}{l}\text { Classificação dos solos } \\
\text { (EMBRAPA, 2006) }\end{array}$ \\
\hline A & S $05^{\circ} 14^{\prime} 42,8^{\prime \prime}$ e W $037^{\circ} 50^{\prime} 17,4^{\prime \prime}$ & Côncava & $\begin{array}{l}\text { Cambissolo Háplico Ta } \\
\text { eutrófico típico }\end{array}$ \\
\hline $\mathrm{B}$ e $\mathrm{C}$ & $\begin{array}{c}\mathrm{S} 05^{\circ} 14^{\prime} 32,8^{\prime \prime} \text { e W } 037^{\circ} 50 ’ 33,8^{\prime \prime} ; \text { S } 05^{\circ} 14^{\prime} 36,3^{\prime \prime} \text { e W } \\
037^{\circ} 50^{\prime} 28,11^{\prime \prime}\end{array}$ & Retilínea & $\begin{array}{l}\text { Cambissolo Háplico } \\
\text { carbonático típico }\end{array}$ \\
\hline $\mathrm{D}$ & S $05^{\circ} 14^{\prime} 24,6 "$ e W $037^{\circ} 50^{\prime} 47,1 "$ & Convexa & $\begin{array}{l}\text { Cambissolo Háplico } \\
\text { carbonático saprolítico }\end{array}$ \\
\hline
\end{tabular}


(Ca e $\mathrm{Mg}$ ) e por titulação (Al). $\mathrm{O}$ pH foi determinado em água, enquanto que a acidez total foi determinada com solução de acetato de cálcio $1 \mathrm{~mol} \mathrm{~L}^{-1}$. Foram calculados os valores da soma de bases (SB), capacidade de troca catiônica (CTC) e saturação por bases (V\%).

A influência da profundidade do solo no crescimento, estado nutricional e na produtividade do bananal foi avaliada a partir da determinação dos seguintes parâmetros: altura da planta mãe (APM), diâmetro do pseudocaule da planta mãe (DPPM), altura da planta filha (APF), massa de folhas frescas (MFF) e secas (MFS), estado nutricional e massa dos cachos da bananeira.

As alturas foram determinadas medindo-se, com auxílio de trena, o comprimento da planta mãe e da filha a partir da superfície do solo até o ponto de inserção da última folha. Já o diâmetro da planta mãe foi calculado a partir de medidas da extensão da circunferência (perímetro) medido com trena a $40 \mathrm{~cm}$ de altura a partir da superfície do solo.

Por ocasião do corte dos cachos para avaliação da produtividade, as folhas das plantas foram retiradas para determinar a massa fresca (MFF) da planta mãe, pesandose diretamente no campo as folhas recém cortadas. $O$ mesmo material foi seco até peso constante para obtenção da massa de folhas secas (MFS). A partir da diferença na massa de folhas frescas e secas, foi determinada a umidade do material vegetal.

A avaliação do estado nutricional foi feita com base na análise química de folhas coletadas na fase de florescimento das plantas. Em cada repetição foi coletada a terceira folha a partir do ápice, retirando 10 $\mathrm{cm}$ da porção central de cada lado das folhas de modo a eliminar a nervura central. Seguindo métodos descritos em Malavolta et al. (1997) foram determinados os teores de fósforo $(\mathrm{P})$, potássio $(\mathrm{K})$, cálcio $(\mathrm{Ca})$, enxofre $(\mathrm{S})$ e sódio $(\mathrm{Na})$ no tecido vegetal.Os dados foram analisados estatisticamente a partir da análise da variância (ANOVA) e da separação de médias pela diferença mínima significativa (DMS) ao nível de 5\%.

\section{Resultados e discussão}

Foram observadas diferenças entre médias de atributos referentes ao crescimento das bananeiras, à massa de folhas frescas e secas, aos teores foliares de $\mathrm{K} \mathrm{e}$ $\mathrm{P}$ e ao acúmulo dos nutrientes $\mathrm{Ca}, \mathrm{K}, \mathrm{Na}, \mathrm{P}$ e $\mathrm{S}$ nas folhas (TAB. $2 ; 3$ e 4$)$. Foi verificada maior altura da planta mãe (APM) nos sítios A (3,4 metros) e C (3,3 metros) que correspondem aos solos com profundidades de 0,92 e $0,65 \mathrm{~m}$, respectivamente $(\mathrm{P}<0,001)$. Por outro lado, a menor APM foi observada no sítio D com valor de 2,7 metros (FIG. 2), correspondendo à área de solo com menor profundidade efetiva (FIG. 3).

Seguindo a tendência da maior APM nos sítios A e C, o diâmetro do pseudocaule da planta mãe (DPPM), que também é uma medida relacionada ao crescimento das plantas, foi maior nesses dois locais $(\mathrm{P}<0,001)$, mas em $\mathrm{C}$ a média não diferiu dos menores valores observados nos sítios D e B (FIG. 4). Entretanto, similarmente ao verificado para a APM, o menor DPPM foi registrado no sítio D onde ocorrem os solos com menor profundidade efetiva. A altura da planta filha (APF) foi similar e maior nos sítios A, C e D, diferindo somente no sítio B no qual a APF apresentou menor valor $(1,1$ metro, $\mathrm{P}<0,001)$.

Em alguns trabalhos é comprovada a influência da profundidade e do volume efetivo do solo no crescimento de espécies vegetais (MEYER et al., 2007; NAGESWARA RAO; JESSY, 2007). Especificamente para bananeira, estudos de crescimento foram feitos levando em consideração a disponibilidade hídrica e não a profundidade do solo, mostrando redução no crescimento das plantas quando há falta de água (FIRTH et al., 2003; MAHOUACHI, 2009).

Tabela 2 - Resumo da análise de variância para atributos referentes ao crescimento e produção das bananeiras: altura da planta-mãe (APM), altura da planta filha (APF), diâmetro do pseudocaule da planta mãe (DPPM), massa de folhas secas (MFS), massa de folhas frescas (MFF), umidade (U) e massa dos cachos (MC)

\begin{tabular}{|c|c|c|c|c|c|c|c|c|}
\hline \multirow{2}{*}{$\begin{array}{l}\text { Fonte de } \\
\text { variação }\end{array}$} & \multirow{2}{*}{ GL } & \multicolumn{7}{|c|}{ Quadrado médio } \\
\hline & & APM & APF & DPPM & MFS & MFF & $\mathrm{U}$ & $\mathrm{MC}$ \\
\hline Tratamentos & 3 & $0,79054 * *$ & $0,9153 * *$ & $47,701 * *$ & $7,1532 * *$ & $40,240 * *$ & $91,65^{\mathrm{ns}}$ & $308,32^{* *}$ \\
\hline Resíduo & 16 & 0,04008 & 0,1248 & 3,793 & 0,3081 & 2,613 & 30,04 & 21,0 \\
\hline Média & & 3,0 & 1,6 & 23,9 & 2,5 & 7,0 & 66,2 & 24,6 \\
\hline CV (\%) & & 6,6 & 21,5 & 8,2 & 22,6 & 22,9 & 8,3 & 18,7 \\
\hline
\end{tabular}

${ }^{* *}$ significativo ao nível de $1 \%$; ${ }^{*}$ significativo ao nível de $5 \%$; ${ }^{\text {ns }}$ não significativo 
Tabela 3 - Resumo da análise de variância para atributos referentes aos teores de nutrientes no tecido vegetal das bananeiras: cálcio $(\mathrm{Ca})$, potássio $(\mathrm{K})$, sódio $(\mathrm{Na})$, fósforo $(\mathrm{P})$ e enxofre $(\mathrm{S})$

\begin{tabular}{ccccccc}
\hline \multirow{2}{*}{ Fonte de variação } & \multirow{2}{*}{ GL } & \multicolumn{6}{c}{ Quadrado médio } \\
\cline { 3 - 7 } & & $\mathrm{Ca}$ & $\mathrm{K}$ & $\mathrm{Na}$ & $\mathrm{P}$ & $\mathrm{S}$ \\
\hline Tratamentos & 3 & $1,274^{\text {ns }}$ & $54,75^{*}$ & $0,002187^{\text {ns }}$ & $1,390387^{* *}$ & $0,01606^{\text {ns }}$ \\
Resíduo & \multirow{2}{*}{16} & 3,188 & 14,79 & 0,002190 & 0,162359 & 0,05403 \\
\cline { 3 - 7 } Média & & 6,9 & 47,7 & 0,5 & 1,3 & 0,8 \\
CV (\%) & & 25,8 & 8,1 & 9,4 & 30,6 & 30,1 \\
\hline
\end{tabular}

** significativo ao nível de $1 \%$; " significativo ao nívelo de $5 \%$; ns não significativo

Tabela 4 - Resumo da análise de variância para atributos referentes ao acúmulo de nutrientes nas folhas das bananeiras: cálcio (Ca), potássio $(\mathrm{K})$, sódio $(\mathrm{Na})$, fósforo $(\mathrm{P})$ e enxofre $(\mathrm{S})$

\begin{tabular}{ccccccc}
\hline \multirow{2}{*}{ Fonte de variação } & \multirow{2}{*}{ GL } & \multicolumn{5}{c}{ Quadrado médio } \\
\cline { 3 - 7 } & & $\mathrm{Ca}$ & $\mathrm{K}$ & $\mathrm{Na}$ & $\mathrm{P}$ & $\mathrm{S}$ \\
\hline Tratamentos & 3 & $295,79^{* *}$ & $15765^{* *}$ & $1,6569^{* *}$ & $2,9802654^{* *}$ & $4,7737^{* *}$ \\
Resíduo & 16 & 30,29 & 606 & 0,1035 & 1,490978 & 0,2925 \\
Média & & 16,7 & 115,9 & 1,2 & 3,2 & 1,9 \\
CV (\%) & & 32,9 & 21,2 & 26,3 & 38,4 & 28,2 \\
\hline
\end{tabular}

** significativo ao nível de $1 \%$;" significativo ao nível de $5 \%$; ${ }^{\text {ns }}$ não significativo

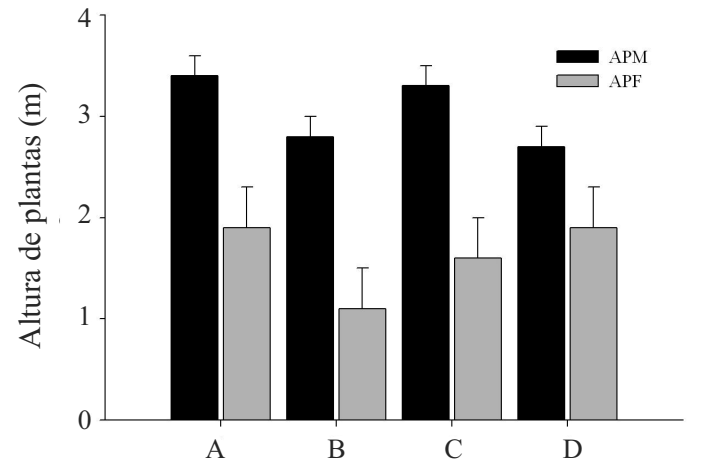

Sítios com diferentes profundidades efetivas do solo

Figura 2 - Médias de altura (m) da planta-mãe (APM) e da planta-filha (APF) nos quatro sítios avaliados (DMS a 5\% de probabilidade). Barras de erro comparam médias de altura de plantas entre sítios para APM e APF

A menor média de altura observada para o sítio de solo mais raso (D) indica que a profundidade do solo e o formato da superfície do terreno podem ter influenciado o crescimento das plantas. Neste caso, é preciso assumir as variações no micro-relevo influenciando a movimentação de água, de modo que, apesar do estudo ter sido conduzido em área irrigada, a menor profundidade do solo e o fluxo hídrico divergente resultaram em meio com menor disponibilidade hídrica para o crescimento das plantas. Segundo Vidal-Torrado et al. (2005), o formato da superfície do terreno influencia a dinâmica dos fluxos hídricos de superfície e subsuperfície e, consequentemente, as propriedades dos solos. Gessler et al. (2000) estudando a variabilidade espacial de atributos de solo, conseguiram explicar de 52 a $88 \%$ da variação com base em informações de formato do terreno (declividade, aspecto). De acordo com os autores, nas superfícies côncavas predomina o acúmulo de água (fluxos hídricos convergentes) e sedimentos, enquanto nas convexas predomina a saída e/ou perda de água e sedimentos (fluxos hídricos divergentes).

Nesse sentido, no presente estudo, o menor crescimento das plantas no sítio D, pode estar associado à redução do volume de água disponível no solo em função, não só da menor profundidade do solo, como também da perda de água condicionada pela forma convexa do terreno neste ponto. Estudos recentes avaliando o efeito das formas do relevo sobre a dinâmica de água no solo indicam realmente que superfícies convexas e mais elevadas estão mais sujeitas a sofrerem déficit hídrico (IQBAL et al., 2005) e a apresentarem menor retenção de água (PACHEPSKY et al., 2001). 


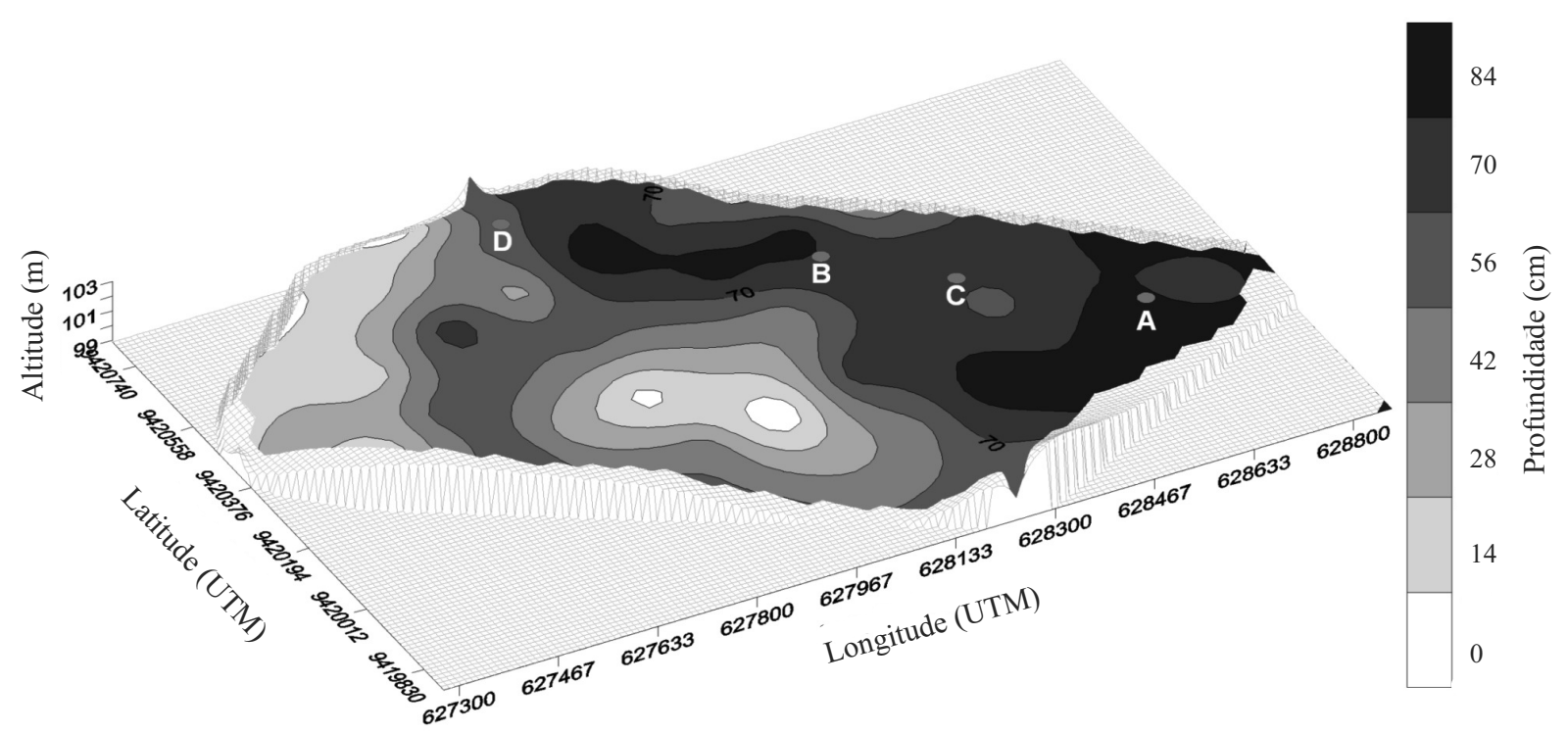

Figura 3 - Mapa de profundidade do solo na área de estudo gerado através da prospecção com tradagens

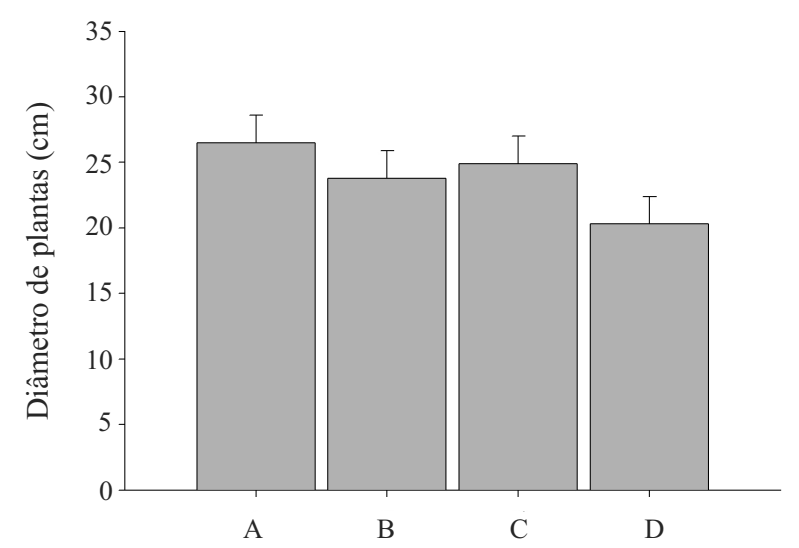

Sítios com diferentes profundidades efetivas do solo

Figura 4 - Médias do diâmetro (cm) do pseudocaule da plantamãe (DMS ao nível de 5\%)

As determinações da massa de folhas frescas (MFF) e massa de folhas secas (MFS) serviram como indicativo da produção de biomassa que não acompanhou a mesma tendência das medidas de crescimento, principalmente em relação ao sítio D. Foi constatado que nos sítios B e $\mathrm{C}$ (solos com profundidade intermediária), houve menor produção de $\operatorname{MFF}\left(5,79\right.$ e 3,7 kg planta $^{-1}$, respectivamente) e MFS (1,9 e 1,1 kg planta ${ }^{-1}$, respectivamente), enquanto que nos sítios $\mathrm{A}$ e $\mathrm{D}$ foram constatadas as maiores médias (8,6 e 9,2 kg planta- de MFF; 3,1 e 3,3 kg planta $^{-1}$ de MFS), representando maior desenvolvimento vegetativo nestes locais (FIG. 5). A MFF encontrada em A e D foi semelhante àquela observada por Yamaguchi e Araki (2004) em bananais do leste africano, que ficaram na faixa de 8 a $10 \mathrm{~kg}$ planta $^{-1}$.

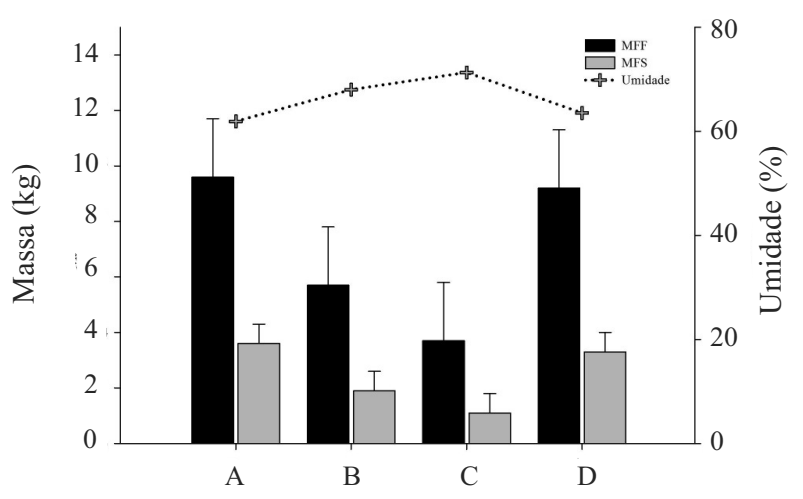

Figura 5 - Médias da massa $(\mathrm{kg})$ de folhas frescas, de folhas secas e umidade (\%) nas folhas de bananeiras cultivadas em quatro sítios com diferentes profundidades efetivas do solo (DMS a 5\% de probabilidade). Barras de erro comparam médias de massa entre sítios para massa fresca e seca

As discrepâncias observadas em A e D quanto ao crescimento em altura, diâmetro do pseudocaule e biomassa de folhas podem ter ocorrido em função dos 
efeitos do micro-relevo na disponibilidade de água e nutrientes, principalmente nitrogênio $(\mathrm{N})$ e potássio (K). A disponibilidade e/ou absorção dos nutrientes em D podem ter sido inadequadas para garantir crescimento em altura e em diâmetro semelhantes ao observado em A, mas não prejudicaram a produção de biomassa de folhas. Melo et al. (2010) estudaram os efeitos do N e $\mathrm{K}$ em diferentes aspectos do crescimento vegetativo de bananeiras, apontando diferenciais quanto ao crescimento em altura, diâmetro do pseudocaule, biomassa seca de folhas e de cachos.

$\mathrm{Na}$ avaliação do estado nutricional foram constatadas diferenças nos teores foliares de fósforo $(\mathrm{P})$ e de potássio $(\mathrm{K})$. No caso do $\mathrm{P}(\mathrm{P}<0,001)$, o maior valor $\left(1,9 \mathrm{~g} \mathrm{~kg}^{-1}\right)$ foi observado para as plantas que cresceram no sítio A (FIG. 6). Esse valor foi próximo àquele encontrado nas folhas de bananeira que cresceram no sítio $\mathrm{C}\left(1,5 \mathrm{~g} \mathrm{~kg}^{-1}\right)$, mas somente o teor foliar das plantas em A foi considerado adequado para a cultura segundo critérios descritos em Malavolta et al. (1997), enquadrando-se próximo ao valor mínimo da faixa de suficiência preconizada pelos autores $\left(1,8\right.$ a $\left.2,7 \mathrm{~g} \mathrm{~kg}^{-1}\right)$. Os maiores valores de $\mathrm{P}$ foliar neste sítio podem estar relacionados tanto às maiores quantidades de $\mathrm{P}$ assimilável no solo deste local (TAB. 5) quanto ao maior volume de solo disponível para ser explorado pelas raízes. De fato, estudos recentes com fruteiras destacam a importância de se obter o máximo volume de raízes em contato com o $\mathrm{P}$ para o adequado suprimento deste nutriente, crescimento das plantas e produção (CORRÊA et al., 2003).
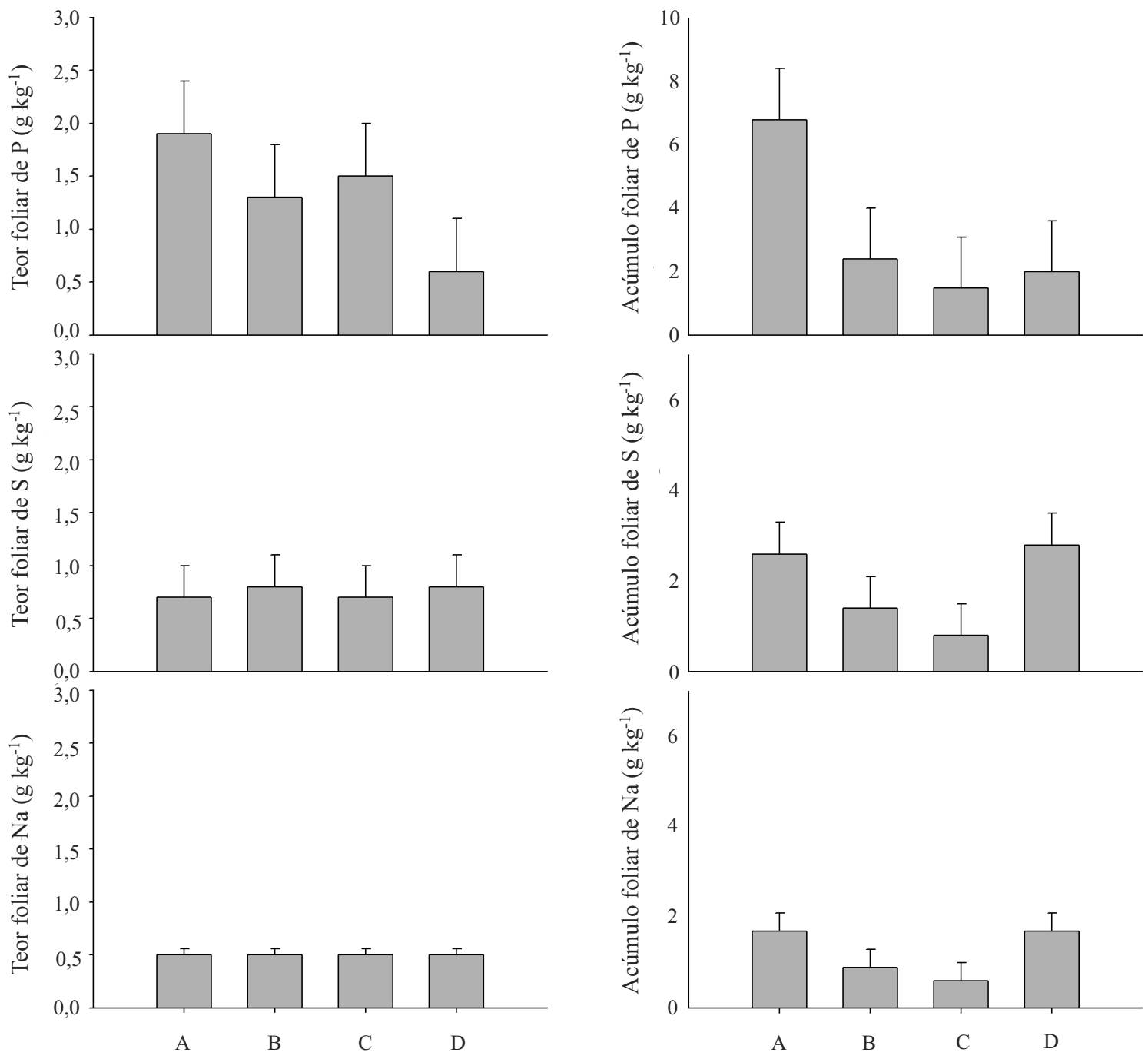

Figura 6 - Médias do teor foliar e acúmulo de fósforo (P), enxofre (S) e sódio $(\mathrm{Na})$ em folhas de bananeiras cultivadas nos sítios A, B, C e D 
Tabela 5 - Caracterização química do solo nos quatro sítios estudados

\begin{tabular}{|c|c|c|c|c|c|c|c|c|c|c|c|c|}
\hline \multirow{2}{*}{ Sítio } & $\mathrm{pH}$ & Corg & $\mathrm{Ca} 2+$ & $\mathrm{Mg} 2+$ & $\mathrm{K}+$ & $\mathrm{Na}+$ & SB & $\mathrm{Al} 3+$ & $\mathrm{H}+\mathrm{Al}$ & CTC & $\mathrm{V}$ & $\mathrm{P}$ \\
\hline & $\mathrm{H}_{2} \mathrm{O}$ & $\mathrm{g} \mathrm{kg}^{-1}$ & \multicolumn{8}{|c|}{ 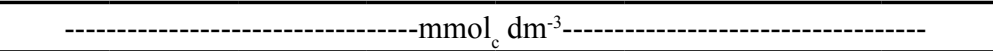 } & $\%$ & $\mathrm{mg} \mathrm{dm}^{-3}$ \\
\hline \multicolumn{13}{|c|}{$0-20 \mathrm{~cm}$} \\
\hline A & 7,0 & 19,3 & 130,0 & 46,0 & 19,0 & 0,0 & 195,0 & 0,0 & 18,0 & 213,0 & 92 & 0,8 \\
\hline B & 8,0 & 13,3 & 218,0 & 30,0 & 9,0 & 2,0 & 259,0 & 0,0 & 0,0 & 259,0 & 100 & 0,0 \\
\hline $\mathrm{C}$ & 7,1 & 20,1 & 218,0 & 76,0 & 21,0 & 0,0 & 315,0 & 0,0 & 21,0 & 336,0 & 94 & 0,0 \\
\hline $\mathrm{D}$ & 7,3 & 20,1 & 166,0 & 56,0 & 18,0 & 0,0 & 240,0 & 0,0 & 12,0 & 252,0 & 95 & 1,1 \\
\hline \multicolumn{13}{|c|}{$20-40 \mathrm{~cm}$} \\
\hline A & 6,8 & 6,9 & 122,0 & 170,0 & 11,0 & 0,0 & 191,0 & 0,0 & 23,0 & 214,0 & 89 & 0,3 \\
\hline B & 8,2 & 7,4 & 212,0 & 138,0 & 4,0 & 2,0 & 243,0 & 0,0 & 0,0 & 243,0 & 100 & 0,0 \\
\hline $\mathrm{C}$ & 7,0 & 8,5 & 220,0 & 186,0 & 8,0 & 1,0 & 305,0 & 0,1 & 22,0 & 327,0 & 93 & 0,0 \\
\hline $\mathrm{D}$ & 7,4 & 9,8 & 172,0 & 160,0 & 9,0 & 1,0 & 255,0 & 0,0 & 5,0 & 260,0 & 98 & 0,1 \\
\hline
\end{tabular}

Com relação ao $\mathrm{K}(\mathrm{P}<0,034)$, o maior teor foliar $\left(51,52 \mathrm{~g} \mathrm{~kg}^{-1}\right)$ foi observado para as plantas amostradas em um dos locais que apresentava solo mais raso, sítio C (FIG. 7). Neste local, o teor foliar do nutriente ficou próximo ao limite superior da faixa de suficiência considerada adequada para a bananeira (35 a $54 \mathrm{~g} \mathrm{~kg}^{-1}$ ) por Malavolta et al. (1997). Nos demais sítios avaliados os teores foliares de $\mathrm{K}$ também foram considerados adequados para a cultura. A suficiência nos teores foliares de $\mathrm{K}$ certamente está relacionada à disponibilidade do nutriente no solo, cujos valores observados na área do presente estudo (TAB. 5) são elevados, se comparados com outros solos do Estado do Ceará (DINIZ, 2007).

Apesar de não ter ocorrido diferença significativa $(\mathrm{P}<0,82)$ entre sítios quanto aos teores foliares de enxofre (S) (FIG. 6), destaca-se o fato de que os teores encontrados ficaram abaixo da faixa de suficiência para a cultura que, de acordo com Malavolta et al. (1997), deve estar entre 2 e $3 \mathrm{~g} \mathrm{~kg}^{-1}$. De acordo com Casagrande et al.(2003), as interações do ânion sulfato com os colóides do solo são expressivas, principalmente com óxidos e hidróxidos de ferro e alumínio, cujas cargas elétricas de superfície variam com o pH e com a força iônica do meio. Estes autores destacam que a adsorção de sulfato diminui progressivamente com a elevação do $\mathrm{pH}$, fato que pode intensificar a perda deste ânion por lixiviação. Assim, no caso dos solos da área de estudo, os elevados valores de $\mathrm{pH}(6,4-8,2$; TAB. 5), característicos de solos calcários, podem ser os responsáveis pelos baixos teores de $\mathrm{S}$ observados. A deficiência em $\mathrm{S}$ provavelmente representa um fator nutricional limitante ao potencial produtivo do bananal em que o estudo foi conduzido.
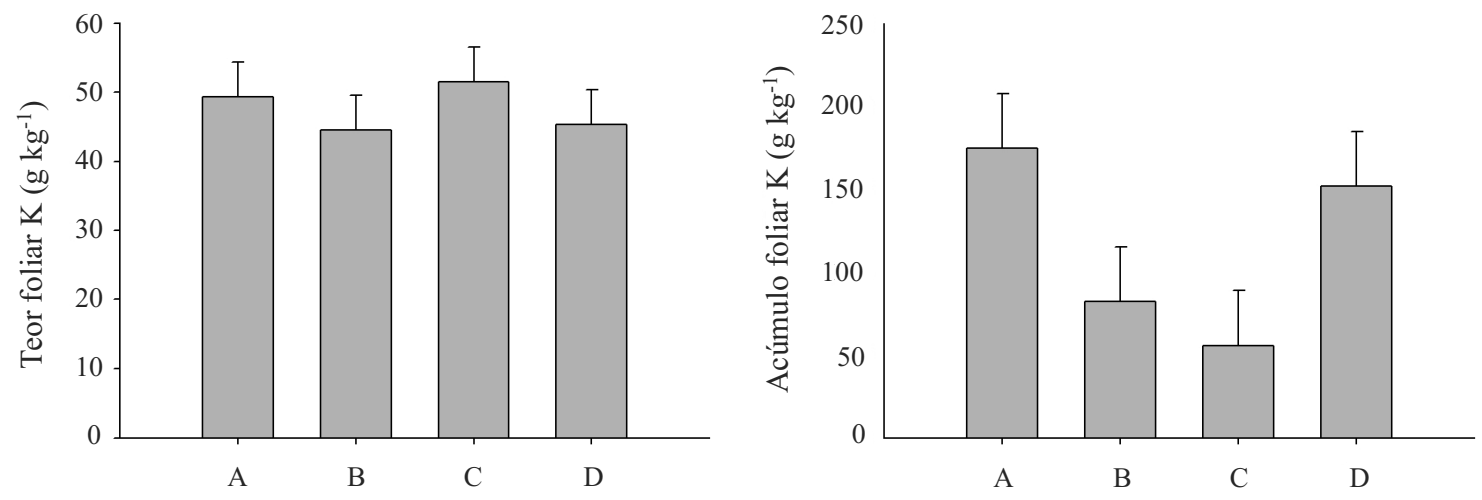

Figura 7 - Médias do teor foliar e acúmulo de potássio $(\mathrm{K})$ em folhas de bananeiras cultivadas nos sítios A, B, C e D 
Não foi observada diferença significativa $(\mathrm{P}<0,75)$ para teores foliares de cálcio (Ca), mas em virtude da elevada disponibilidade de cálcio no solo da área estudada, teores foliares do nutriente ficaram dentro da faixa considerada adequada por Malavolta et al. (1997) (FIG. 8). De acordo com os dados apresentados, observa-se que os valores de Ca no solo encontram-se elevados quando comparados com as outras bases $(\mathrm{Mg}, \mathrm{Na}$ e $\mathrm{K})$. Este fato deve-se à influência do material de origem, o calcário da Formação Jandaíra, que condiciona as altas concentrações de Ca. Estes resultados foram também observados em outros estudos realizados na Chapada do Apodi (MOREIRA et al., 2007).

Com os dados referentes à biomassa de folhas secas e do teor foliar, foi possível determinar o acúmulo de nutrientes nas folhas (FIG. 6; 7 e 8), estimando a absorção de nutrientes pelas folhas. Maior acúmulo de fósforo $(\mathrm{P})$ ocorreu nas plantas do sítio $\mathrm{A}$, enquanto que o maior acúmulo de enxofre $(\mathrm{S})$, sódio $(\mathrm{Na})$, cálcio $(\mathrm{Ca})$ e potássio $(\mathrm{K})$ foi observado em A e $\mathrm{D}$, principalmente em função dos maiores valores de biomassa de folhas secas. Similarmente ao observado neste estudo, Cavalcante et al. (2005) encontraram que $\mathrm{o}$ acúmulo de $\mathrm{P}$ nas diferentes partes de bananeiras foi mais influenciado por suas massas que pelos teores do elemento no tecido vegetal. Hoffmann et al. (2010) também verificaram que os cultivares de banana que extraíram maiores quantidades de macronutrientes foram os que acumularam mais quantidade de matéria seca.

No sistema de manejo do bananal estudado, as folhas retornam ao solo por ocasião da colheita dos cachos, contribuindo com a ciclagem dos nutrientes. Porém, se o padrão de acúmulo de nutrientes nos frutos for semelhante ao que foi observado nas folhas, especial atenção deverá ser destinada ao manejo da adubação nos sítios A e D. Esta afirmação deve-se ao fato de que os nutrientes dos cachos são exportados pelas colheitas, empobrecendo o solo e causando desequilíbrios entre nutrientes. Como já foi bem relatado por Baijukya (1998), a colheita das bananas, bem como a retirada dos restos culturais da área cultivada caracterizam formas de saída no fluxo dos nutrientes nas propriedades agrícolas. Crisóstomo et al. (2008) recomendam adubação NPK em bananeiras cultivadas em solos arenosos do Vale do Curu (CE), mesmo não havendo resposta à adubação no primeiro ciclo do cultivo. Os autores fundamentam sua recomendação no fato de que a exportação de nutrientes pela cultura, principalmente $\mathrm{K}$, é elevada.

Como indicativo de produção, a massa dos cachos diferiu entre locais $(\mathrm{P}<0,001)$, com maior média $(31,6 \mathrm{~kg})$ observada em A (FIG. 9A). Yamaguchi e Araki (2004) verificaram médias da massa dos cachos de bananeiras variando entre 33 e $40 \mathrm{~kg}$ planta $^{-1}$. Mesmo em se tratando de plantio realizado em diferentes condições de clima e solo, e mesmo sem haver especificação a respeito do ciclo de colheita, a massa dos cachos encontrada pelos autores pode ser comparada com a obtida no presente estudo, evidenciando melhor potencial produtivo para a bananeira cultivada em solo mais profundo. Contudo, no sítio $\mathrm{D}$ o peso de cachos foi superior ao verificado em B e C que possuem maiores profundidades efetivas que D. É possível que os mesmos fatores responsáveis pela elevada produção de biomassa de folhas secas em $\mathrm{D}$ foram os responsáveis pelo maior peso de cachos quando comparado aos sítios $\mathrm{B}$ e $\mathrm{C}$.

Foi observada correlação positiva e significativa entre massa de folhas secas e massa dos cachos (FIG. 9B). Porém, mesmo que as bananeiras em $\mathrm{D}$ tenham produzido biomassa de folhas semelhante ao observado em A, a menor
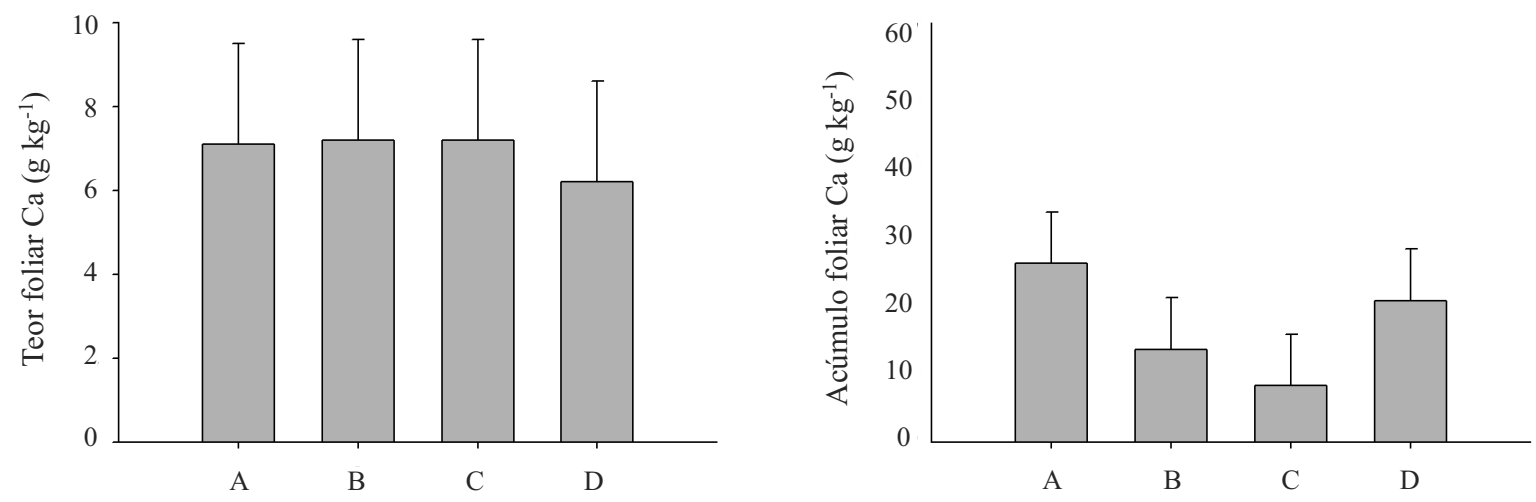

Figura 8 - Médias do teor foliar e acúmulo de cálcio em folhas de bananeiras cultivadas nos sítios A, B, C e D 

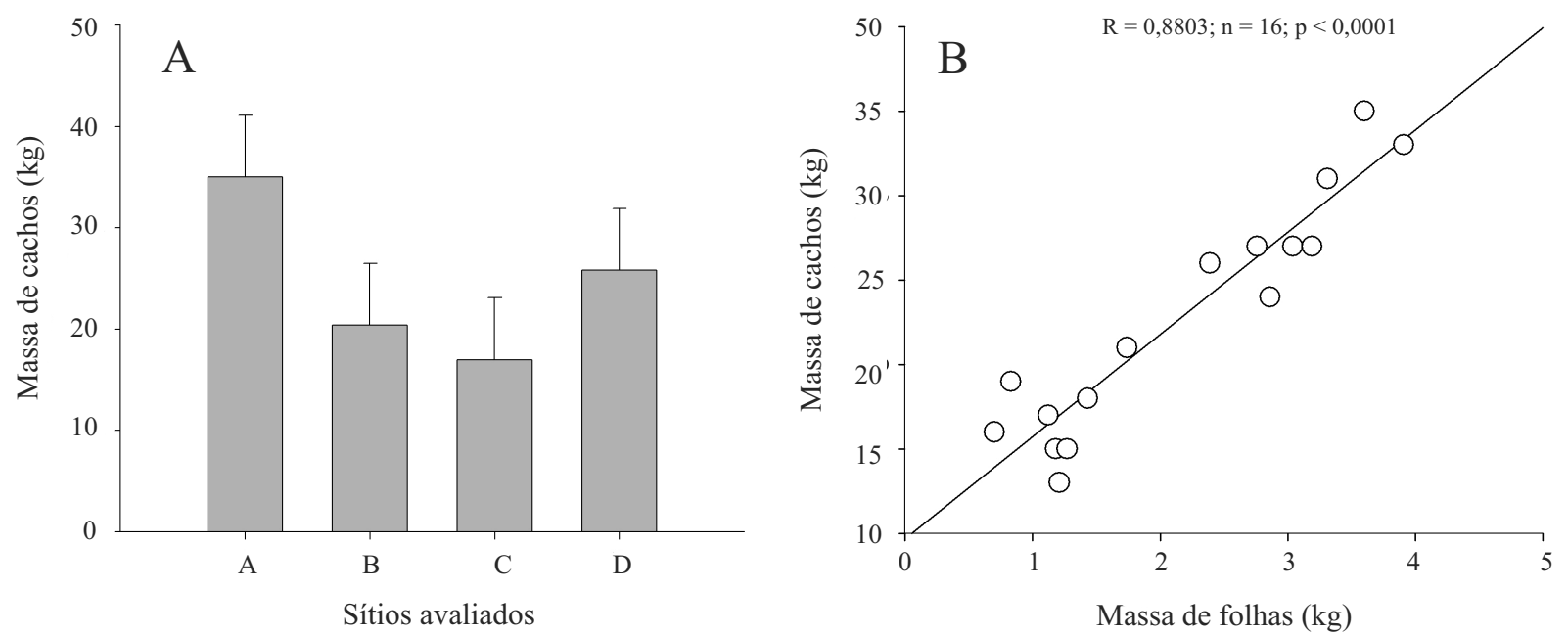

Figura 9 - Média da massa dos cachos das bananeiras cultivadas nos diferentes sítios (A) e correlação entre massa de folha seca e massa dos cachos das bananeiras (B)

profundidade efetiva do solo resultou em menor vigor de plantas e, conseqüentemente, em menor massa dos cachos. Araya e Blanco (2001) associaram o desenvolvimento de bananeiras classificado como "regular a bom" às condições do solo que permitiram o aprofundamento do sistema radicular até $120 \mathrm{~cm}$. Já a classe de desenvolvimento definida como "pobre" foi associada à menor profundidade efetiva de raízes das plantas $(75 \mathrm{~cm})$.

Assim, as menores massas dos cachos observadas em $\mathrm{B}, \mathrm{C}$ e $\mathrm{D}$ podem estar relacionadas ao impacto da menor profundidade do solo $(0,77$; 0,65 e $0,52 \mathrm{~cm}$, respectivamente) sobre o sistema radicular das bananeiras nestes pontos. Mas também é importante destacar a ocorrência de má drenagem em B e C, especialmente em épocas chuvosas. Estes eventos ocorrem devido à localização dos sítios na superfície retilínea, que apesar de apresentar fluxo de água divergente, favorece o acúmulo de água no perfil do solo na estação chuvosa (FIG. 1). No sítio A, apesar do fluxo convergente de água, a maior profundidade efetiva permite que o sistema radicular não fique em condições saturadas.

Em estudo recente realizado com cv. Williams (o mesmo da área de estudo), Aguilar et al. (2003) demonstram que a deficiência de $\mathrm{O}_{2}$, causada pela má drenagem, afeta, nos primeiros minutos, a condição de aeração do sistema radicular e, consequentemente, dentro de algumas horas, prejudica as funções radiculares (elongamento e transporte de solutos), impactando negativamente a produção. De fato, Turner (2003), destaca a condição de drenagem do solo como um dos aspectos chave para a produção da banana.

\section{Conclusões}

1. O solo mais profundo favoreceu o teor de fósforo e o acúmulo de fósforo, potássio e cálcio nas folhas das bananeiras, resultando em maior massa dos cachos;

2. A profundidade efetiva do solo e o micro-relevo influenciam o crescimento e o potencial produtivo de bananeiras irrigadas, pois afetam a dinâmica da água no solo e, provavelmente, o sistema radicular das plantas.

3. Estudos futuros são necessários para verificar como a profundidade efetiva do solo afeta a distribuição de raízes das bananeiras irrigadas e o estado nutricional das plantas quanto a nutrientes que não foram abordados no presente estudo.

\section{Agradecimentos}

Ao Banco do Nordeste do Brasil (BNB) pelo auxílio financeiro. À Agrícola Famosa pela concessão da área de estudo. Aos Engenheiros Agrônomos Michel Cosme e João Paulo Cajazeira pelo apoio de campo.

\section{Referências}

AGUILAR, E. A. et al. Oxygen distribution and movement, respiration and nutrient loading in banana roots (Musa spp. L.) subjected to aerated and oxygen-depleted environments. Plant and Soil, v. 253, p. 91-102, 2003. 
ARAYA, M. Stratification and spatial distribution of the banana (Musa AAA, Cavendish subgroup, cvs Valery and Grande Naine) root system. In: TURNER, D. W.; ROSALES, F. E. eds. Banana root system: towards a better understanding for its productive management. Proceedings of an international symposium. France, Montpellier: INIBAP. 2005. p. 83-103.

ARAYA, M.; BLANCO, F. Changes in the stratification and spatial distribution of the banana (Musa AAA cv. Grand Naine) root system of poor, regular, and good developed plants. Journal of Plant Nutrition, v. 24, n. 11, p. 16791693, 2001.

BAIJUKYA, F. P., STEENHUIJSEN PETERS, B. Nutrient balances and their consequences in the banana-based land use systems of Bukoba district, northwest Tanzania. Agriculture, Ecosystems and Environment, v. 71, p. 147-158, 1998.

CASAGRANDE, J. C. et al. Adsorção de fosfato e sulfato em solos com cargas elétricas variáveis. Revista Brasileira de Ciência do Solo, v. 27, p. 51-59, 2003.

CAVALCANTE, A. T.; SAMPAIO, E.V. S.B.; CAVALCANTE, U. M. T. Interdependência na absorção e redistribuição de fósforo entre planta-mãe e filha da bananeira. Revista Brasileira de Fruticultura, v. 27, n. 02, p. 255-259, 2005.

CORRÊA, M. C. M. et al. Resposta de mudas de goiabeira a doses e modos de aplicação de fertilizante fosfatado. Revista Brasileira de Fruticultura, v. 25, p. 164-169, 2003.

CRISÓSTOMO, L. A. et al. Influência da adubação NPK sobre a produção e qualidade dos frutos de bananeira cv. "Pacovan" 1. Revista Ciência Agronômica, v. 39, n. 01, p. 45-52, 2008.

DINIZ, S. F. et al. Fontes de Potássio não trocável e potássio total em quatro solos do estado do Ceará. Geociências, v. 26, n. 04, p. 379-386. 2007.

DNOCS - DEPARTAMENTO NACIONAL DE OBRAS CONTRA AS SECAS. Perímetro irrigado JaguaribeApodi. Disponível em: http://www.dnocs.gov.br/ dnocs/ doc/canais/perimetros_irrigados/ce/jaguaribe_apodi.html. Acesso em: 06 mai. 2009.

EMBRAPA. Sistema Brasileiro de Classificação do Solo. 2. ed. Rio de Janeiro: Embrapa Solos, 2006. 306p.

EMBRAPA.. Manual de métodos de análise de solo.2.ed. Rio de Janeiro: Embrapa Solos, 1997. 212p.

FIRTH, D. J.; JOHNS, G. G.; WHALLEY, R. D. B. Glasshouse and field studies on the effects of groundcovers on banana and macadamia growth and water relations. Australian Journal of Experimental Agriculture, v. 43, p. 1245-1254, 2003.

GESSLER, P. E. et al. Modeling Soil-Landscape and Ecosystem Properties Using Terrain Attributes. Soil Science Society of America Journal, v. 64, p.2046-2056, 2000.

HOFFMANN, et al. Acúmulo de matéria seca e de macronutrientes em cultivares de bananeira irrigada. Revista Brasileira de Fruticultura, v. 26, p. 01-10, 2010.

IBGE. Estatística agricultura. Disponível em: $<$ http://www.sidra. ibge.gov.br>. Acesso em: 09 jul. 2010.
IQBAL, J. et al. Relationships between Soil-Landscape and Dryland Cotton Lint Yield. Soil Science Society of America Journal, v. 69, p. 872-882, 2005.

LEMOS, M. S. S. et al. Evaluation of characteristics of cambisols derived from limestone in low tabelands in northeaster Brazil: Implications for management. Pesquisa Agropecuária Brasileira, v. 32, n. 08, 1997.

MAHOUACHI, J. Changes in nutrient concentrations and leaf gas exchange parameters in banana plantlets under gradual soil moisture depletion. Scientia Horticulturae, v. 120, p. 460-466, 2009.

MAIA, C. E.; MORAIS, E. C; OLIVEIRA, M. Classificação da água de irrigação utilizando quatro metodologias de cálculo para razão de adsorção de sódio - II. Região do Baixo Açu, Rio Grande do Norte. Caatinga, v. 11, n. 1/2, p. 47-52, 1998.

MALAVOLTA, E.; VITTI, G.C.; OLIVEIRA, S.A. de. Avaliação do estado nutricional das plantas: princípios e aplicações. 2.ed. Piracicaba: POTAFOS, 1997. 319p.

MELO, A. S. et al. Crescimento, produção de biomasa e eficiência fotossintética da bananeira sob fertirrigação com nitrogênio e potássio. Revista Ciência Agronômica, v. 41, n. 03, p. 417-426, 2010.

MEYER, M. D.et al. Influence of soil thickness on stand characteristics in a Sierra Nevada mixed-conifer forest. Plant and Soil, v. 294, p. 113-123, 2007.

MOREIRA, J. N. et al. Caracterização física e química de solos do assentamento de reforma agrária Maísa em Mossoró, RN. Revista de Biologia e Ciências da terra, v. 07, n. 02, p. 49-55, 2007.

NAGESWARA RAO, D. V. K.; JESSY, M. D. Impact of effective soil volume on growth and yield of rubber (Hevea brasiliensis). Geoderma, v. 141, n. 03-04, p. 332-340, 2007.

OLIVEIRA, D. P. de et al. Geoestatística e modelo numérico de terreno em ciências do solo: estudo de caso na Chapada do Apodi - CE. In: SIMPÓSIO BRASILEIRO DE SENSORIAMENTO REMOTO, 14., 2009, Natal. Anais... Natal: INPE, 2009. p. 4141-4147.

PACHEPSKY, Y. A.; TIMLIN, D. J.; RAWLS, W. J. Soil Water Retention as Related to Topographic Variables. Soil Science Society of America Journal, v. 65, p.1787-1795, 2001.

ROMANYA, J., VALLEJO, V. R. Productivity of Pinus radiata plantations in Spain in response to climate and soil. Forest Ecology and Management, v. 195, p. 177-189, 2004.

SOUZA, L. S. et al. Distribuição do sistema radicular de citros em uma toposseqüência de solos de tabuleiro costeiro do estado da Bahia. Revista Brasileira de Ciência do Solo, v. 32, p. 503-513, 2008.

SOUZA, Z. M. et al. Small rilief shape variantions influence spatial variability of soils chemical attributes. Scientia Agricola, v. 63, n. 02, p. 161-168, 2006.

TURNER, D.W. Factors affecting the physiology of the banana root system. In: TURNER, D. W.; ROSALES, F. E., Eds, Banana Root System: Towards a better understanding for 
its Productive Management. Proceedings of an International Symposium held in Costa Rica, San José: INIBAP. 2003.p. 107-113.

VIDAL-TORRADO, P.; LEPSCH, I. F.; CASTRO, S. S. Conceitos e aplicações das relações pedologia-geomorfologia em regiões tropicais úmidas. In: VIDAL-TORRADO et al. (Org.). Tópicos em Ciência do Solo. Viçosa: Sociedade Brasileira de Ciência do Solo, 2005. v. 4, p. 145-192.

WAISEL, Y.; ESHEL, A.; KAFKAFI, U. eds. Plant roots - the hidden half. 3.ed. New York: Marcel Dekker, 2002. $1136 \mathrm{p}$.
WANG, J.; ENDRENY, T. A.; HASSETT, J. M. Power function decay of hydraulic conductivity for a TOPMODEL-based infiltration routine. Hydrological Processes, v. 20, p. 38253834,2006

WEBER, O. B. et al. Adubação nitrogenada e potássica em bananeira "Pacovan" (Musa AAB, subgrupo prata) na Chapada do Apodi, Estado do Ceará. Revista Brasileira de Fruticultura, v. 28, n. 01, p. 154-157, 2006.

YAMAGUCHI, J.; ARAKI, S. Biomass production of banana plants in the indigenous farming system of the East African Highland. A case study on the Kamuchumu Plateau in Northwest Tanzania. Agriculture, Ecosystems and Environment, v. 102, p. 93-111, 2004. 